\title{
$\widehat{A}$ Madridge \\ madridge Journal of Surgery \\ Interconnecting Scientific World
}

Case Report

Open Access

\section{Proximal Phalanx Shortening for correction of Flexible Toe Deformities}

\author{
David B Kay ${ }^{\star}$ and James A Sabetta ${ }^{2}$ \\ IProfessor of Orthopedic Surgery, Northeast Ohio Medical University, Crystal Clinic Orthopedic Center, OH, USA \\ ${ }^{2}$ Crystal Clinic Orthopedic Center, OH, USA
}

\section{Article Info \\ *Corresponding author: \\ David B Kay \\ Professor \\ Department of Orthopedic Surgery \\ Northeast Ohio Medical University \\ Crystal Clinic Orthopedic Center \\ 3975 Embassy Pkwy \\ Akron, $\mathrm{OH} 44333$ \\ USA \\ E-mail: Dbkay50@gmail.com}

Received: May 3, 2018

Accepted: May 23, 2018

Published: May 29, 2018

Citation: Kay DB, Sabetta JA. Proximal Phalanx Shortening for correction of Flexible Toe Deformities. Madridge J Surg. 2018; 1(2): 34-37.

doi: $10.18689 / \mathrm{mjs}-1000108$

Copyright: @ 2018 The Author(s). This work is licensed under a Creative Commons Attribution 4.0 International License, which permits unrestricted use, distribution, and reproduction in any medium, provided the original work is properly cited.

Published by Madridge Publishers

\begin{abstract}
Lesser toes that are longer than the great toe can present both functional and painful problems. The toes can be categorized as rigid or flexible deformities. The preferred method to correct the rigid deformities is to fuse the proximal interphalangeal (PIP) joint. The flexible deformity offers another option of proximal phalanx shortening with soft tissue balancing. This paper details the technique of joint sparing correction of symptomatic flexible toes.
\end{abstract}

Keywords: Proximal phalanx; Correction; Flexible toe; Deformities.

\section{Introduction}

The paper will use the definition of a claw toe where the extension of the proximal phalanx at the MTP joint and flexion through the PIP joint. This procedure can also be used to correct a flexible hammertoe as well. A hammertoe does not have extension at the MTP joint. A crossover toe is a toe that overlaps an adjacent toe. A long toe is one where the normal parabola of the forefoot is not within an accepted range and the previously described clinical complaints are present. Please refer to figures 1 and 2. It is important to assess the toes when the foot is in a weight bearing position. The procedure does not preclude any soft tissue balancing that may be needed to place the toe in a neutral position.

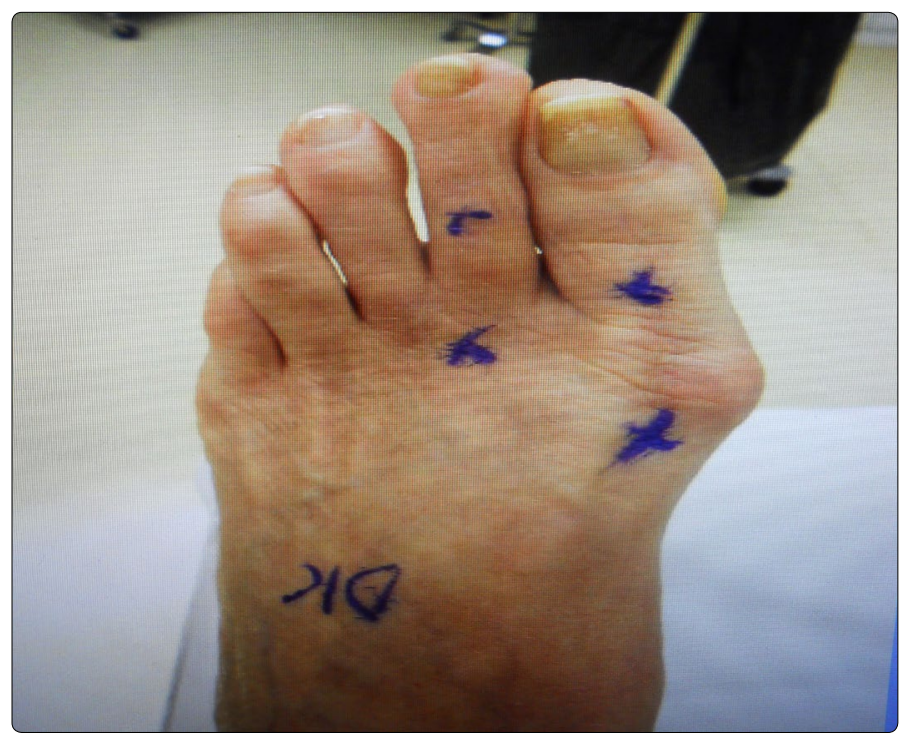

Figure 1. This picture shows the patient preoperative. Note the length of the second toe in relation to the hallux and the third toe. The patient had a symptomatic bunion deformity addressed at the time of the second toe shortening 


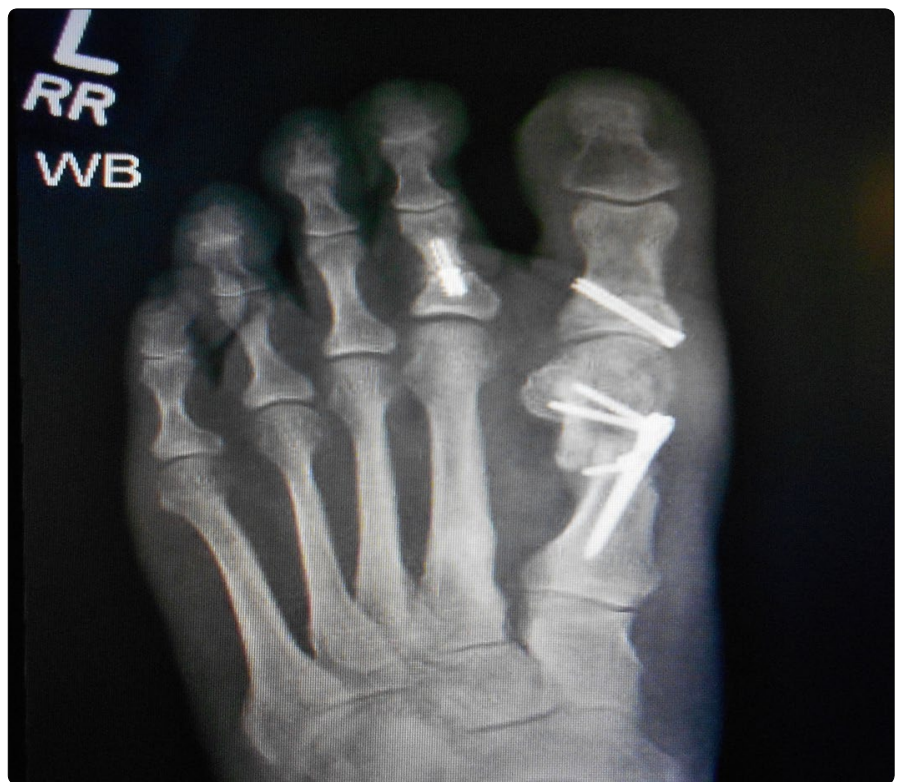

Figure 2. The second toe was addressed through the proximal phalanx with an asymmetric shortening osteotomy to correct the varus angulation.

The hallux valgus deformity was corrected with a double osteotomy bunionectomy technique. Fixation was obtained using the Wright Medical Mini Maxlock ISO plate system and Mini Maxtorque screws

Claw and hammertoes are common foot deformities. They may be associated with other problems of the forefoot. The associated conditions may include instability of the metatarsophalangeal (MTP) joint, dislocation of the MTP joint, Morton's neuroma, hallux valgus or hallux rigidus $[1,6]$. A lesser toe that is excessively long, when compared to the large toe, can cause several problems. The second toe is typically the most common of the toes affected. The length of the toe may make shoe fit difficult and painful with or without callosities at the proximal interphalangeal (PIP) joint. There may be pain and nail deformity because of the pressure of the shoe on the distal aspect of the toe. When conservative treatment fails, many surgical options can be proposed, but the ideal technique has yet to be found $[2,4,5,6,7,8]$. Over the years in my practice patients have complained about too straight toe, a floating toe, painful recurvatum, mallet toe and pin tract infections with the many different ways to address a painful claw toe [2]. Most operative descriptions do not delineate if the PIP deformity is rigid of flexible. The PIP joint is commonly addressed by resection of the distal condyles of the proximal phalanx seeking either rigid fibrous or osseous union [3]. The use of removable wire implants is the most common form of fixation. However, no fixation, resorbable pins, staples and intramedullary implants have all been described to stiffen the joint and shorten the toe. There are a group of patients that will present with a long toe that is flexible at the PIP joint. It would seem unnecessary to sacrifice the PIP joint in order to balance the toe. This procedure allows for motion of the joints that are mobile and painless. If there is recurrent deformity at the PIP joint, then having flexibility of the joint allows for better shoe fit than when it is arthrodesed. If a floating toe occurs, then the new deformity will be not as obvious functionally with a mobile PIP joint. This paper details a procedure of joint sparing correction with intramedullary fixation of the flexible claw and hammer toe.

\section{Methods}

This procedure was performed on 30 patients by the senior author over a 6-month period. The implant that was selected is the Cannu Link (Wright Medical, Memphis, TN). This is a cannulated implant that is primarily used for PIP joint fusions for claw and hammertoe correction. The placement over a guide wire allows for precise reaming and placement. An added benefit is the ability to cross pin the MTP joint if needed to maintain the correction after extensive soft tissue releases. There are times when only minimal shortening is needed and a basal osteotomy can be performed without fixation. This type of osteotomy is recommended for residual deformity that can occur with a cross over toe.

Patients were advised to remain non-weight bearing for a one week period then begin weight bearing with a postoperative boot for 6 -weeks. They were then weaned into roomy, comfortable shoes. Patients could then increase activities as tolerated. All of the patients were able to resume activities of daily living and recreational activities by the 3-month visit.

Minor complications included superficial wound infections and mild dehiscence. All of these were treated conservatively with good resolution.

\section{Surgical description}

The toe is approached from either a dorsal midline or dorsal-lateral incision. The extensor mechanism is resected and the PIP and MTP joints should be exposed. Do not skeletonize the phalanx. It is critical to identify the joints so the osteotomies are correctly placed. I will balance the MTP joint grossly with release of the dorsal capsule, collateral ligament release, extensor mechanism lengthening or harvest of the extensor digitorum brevis tendon slip if it is to be used in a sub-intermetatarsal tendon transfer. The length of the shortening is determined by measuring the difference in the lengths to the adjacent toe, usually a segment between 5-10 $\mathrm{mm}$ in length. When the metatarsal is also to be shortened this needs to be taken into account. If the toe is medially deviated, a trapezoidal shape, wider laterally, may be removed to provide additional correction of this deformity. When the toe is dorsiflexed, the trapezoidal plantar base may be longer to slightly plantar flex the toe. When it is a combined deformity, then a wider base both plantar and laterally maybe used to provide correction beyond soft tissue balancing alone. The amount of bone removed is actually quite small. Precision is key with technique and instrumentation.

It is important that when preforming the osteotomy that the first saw cut is not completed. It becomes a technical challenge to complete the second cut because of the instability of the phalanx. A partial cut of the first osteotomy followed by completion of the second osteotomy. Return to the initial osteotomy to complete it. The bone segment is completely removed. If there is a need to perform a flexor digitorum longus transfer, the tendon is readily accessed.

The guide wire is placed by hand in the intramedullary 
canal of the distal segment of the phalanx. Placement under power is usually not needed and can result in improper guide wire placement. The canal is reamed to size so that the largest implant will have a snug fit. The smallest guide wire is inserted under power into the proximal segment. It is critical not to place the osteotomy too proximal or there will not be space for the screw component of the implant. The guide wire must be perpendicular to the segment otherwise a new deformity will be created. The proximal segment can be pinned to the metatarsal head if needed for stabilization during the insertion of the implant. The wire is now removed from the proximal segment and if anticipated that the MTP joint will need shortterm stabilization then the guide wire is reinserted into the distal segment and drilled out through the end of the toe. The cannulated stem of the implant is then inserted in the guide wire. If no additional fixation is needed then the stem is inserted into the prepared canal and the bone segments are pushed together. Pay attention to rotation so that the nail beds of the adjacent toes are parallel. If there is not circumferential bone contact, morsellization of the removed bone can be used for local grafting.

It is important not to remove excessive bone otherwise the now extra soft tissue will give the appearance of a "fat" toe. Also, the bone shortening effectively lengthens the soft tissues and may contribute to a "floppy" toe.

A variation of the osteotomy is to remove a small wedge of bone at the metadiaphyseal junction. This can be useful when there is a residual deformity of the toe after the soft tissue rebalancing. The far cortex is left intact and the osteotomy is "greensticked". Usually no fixation is needed.

An advantage to maintaining a flexible toe can be seen after a metatarsal osteotomy. The 'floating toe' is a welldescribed complication. When the PIP joint is arthrodesed the toe becomes problematic because of the stiffness of the toe. A flexible joint can somewhat disguise the deformity. Please refer to figure 3 .

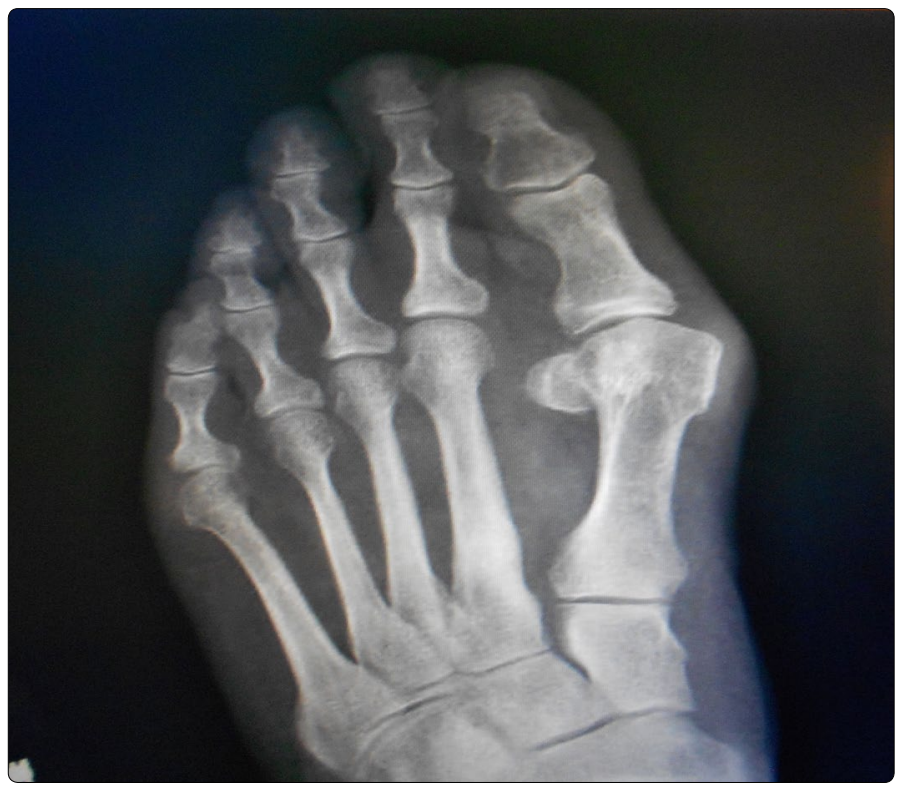

Figure 3. This radiograph shows the relative length of the second toe in relation to the third toe. The hallux valgus deformity can also be appreciated on the film

\section{Summary}

Claw toes can present a challenge for reconstruction. Many options exist for the treatment of hammertoes and claw toes, both operative and non-operative. Surgical management of these deformities is one of the most common procedures performed on the forefoot [5]. The goal is to create toes that are not just pain free but also functional. Preservation of a functioning joint should be considered. There have been reports that a toe "to straight, hyperextended, or not touching the ground" leads to greater dissatisfaction among patients [2]. No rotational deformities have been noted in patients. Post-operative complaints have been limited to swelling and tenderness resolving at 6 months to a year. We have had less than a $5 \%$ non-union rate and no implants (figure 4) have migrated or required further surgical intervention. We noted no intra operative fractures during this procedure. The procedure is not technically demanding, but attention to detail on each step is necessary. These anatomic structures are very small and poor technique will be difficult to salvage. This procedure is an alternative to PIP fusion for a flexible hammertoe associated with a symptomatically long toe.

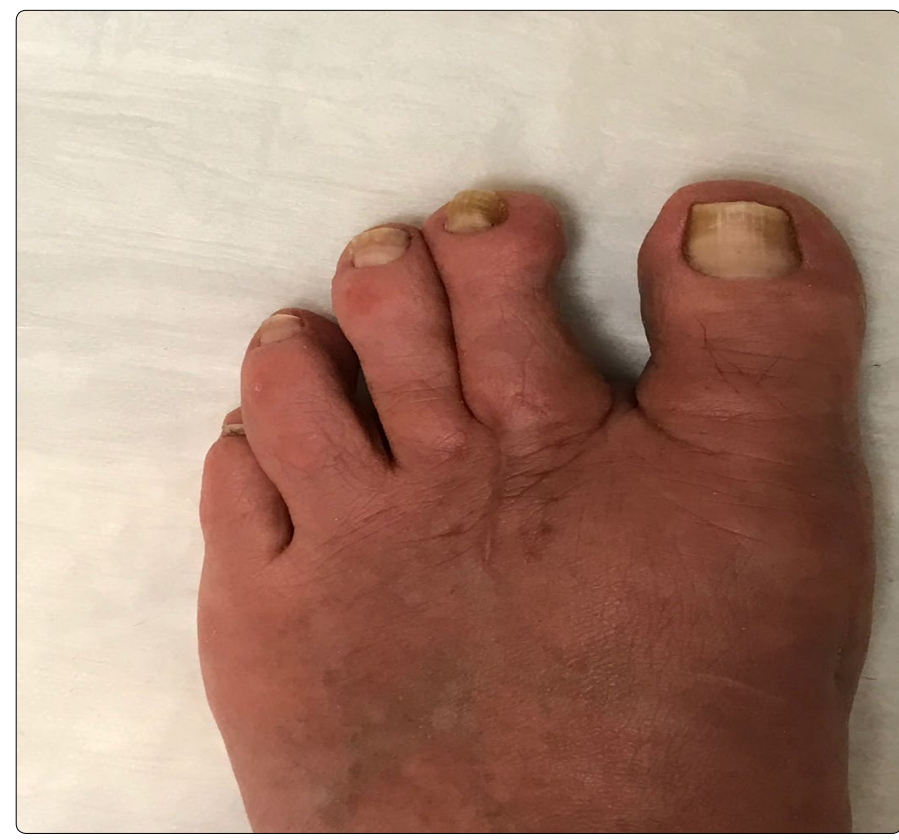

Figure 4. At five weeks the toes continue to maintain good position and retain a proper lesser toe cascade

\section{Conclusion}

Proximal phalanx shortening is a joint preservation strategy that allows for correction of angulation in all planes as well as rotation through the use of rigid intramedullary fixation. The technique is straightforward and offers advantages over joint resection or joint fusion for the management of flexible deformities of the lesser toes.

\section{References}

1. Caterini R, Farsetti P, Tarantino U, Potenza V, Ippolito E. Arthrodesis of the toe joints with an intramedullary cannulated screw for correction of hammertoe deformity. Foot and Ankle Int. 2004; 25(4): 256-261. doi: $10.1177 / 107110070402500411$ 
2. Konkel K, Menger A, Retzlaff S. Hammer toe correction using an absorbable intramedullary pin. Foot and Ankle Int. 2007; 28(8): 916-920. doi: 10.3113/ FAl.2007.0916

3. Klammer G, Baumann G, Moor B Farshad M, Espinosa N. Early complications and recurrence rates after kirschner wire transfixation in lesser toe surgery: a prospective randomized study. Foot and ankle Int. 2012; 33(2): 105-112. doi: 10.3113/FAl.2012.0105

4. Scholl A, McCarty J, Scholl D. Smart toe ${ }^{\circledR}$ implant versus buried kirschner wire for proximal interphalangeal joint arthrodesis: a comparative study. J Foot and Ankle Surg. 2013; 52(5): 580-583. doi: 10.1053/j.jfas.2013.02.007

5. Ellington JK, Anderson RB, Davis WH, Cohen BE, Jones CP. Radiographic analysis of proximal interphalangeal joint arthrodesis with an intermedullary fusion device for lesser toe deformities. Foot and Ankle Int. 2010; 31(5): 372-376. doi: 10.3113/FAI.2010.0372
6. Basile A, Albo F, Via AG. Intramedullary fixation system for the treatment of hammertoe deformity. J Foot and Ankle Surg. 2015; 54(5): 900-916. doi: 10.1053/j.jfas.2015.04.004

7. Harris W 4th, Mote GA, Malay DS. Fixation of the proximal interphalangeal arthrodesis with the use of an intraosseous loop of stainless steel wire suture. J Foot and Ankle Surg. 2009; 48(3): 411-414. doi: 10.1053/j.jfas.2009.01.012

8. Canales MB, Razzante MC, Ehredt DJ Jr, Clougherty CO. A simple method of intramedullary fixation for proximal interphalangeal arthrodesis. $J$ foot and Ankle Surg. 2014; 53(6): 817-824. doi: 10.1053/j.jfas.2014.03.017 